\title{
La Di-ferencia de la Traducción
}

\author{
Assumpta Camps • \\ Universidad de Barcelona
}

La traducción no ha contado, hasta hace relativamente poco, con un estatus reconocido en la teoría literaria, ni en la historia de la literatura. Tradicionalmente se la ha considerado una actividad de segundo orden, excepto en lo que se refiere a la hermenéutica bíblica. Sin embargo, el discurso sobre la traducción se ha enriquecido mucho con la aportación de críticos y pensadores del siglo XX no directamente preocupados por la traducción en sí, pero cuya labor ha evidenciado la relevancia, e incluso la centralidad, que la traducción ocupa en su pensamiento y en sus escritos. En la reflexión contemporánea, las cuestiones teóricas que plantea la traducción han dejado de ser marginales para pasar a adquirir una relevancia indiscutible en la crítica post-estructuralista sobre el lenguaje y la cultura.

Uno de los aspectos claves en este sentido ha sido, sin lugar a dudas, la reflexión en torno a la inestabilidad del significado original, o, si se prefiere, la dicotomía original/copia, reflejadas en la relación entre el texto original y su traducción. La aproximación a la Desconstrucción, por un lado (en su cuestionamiento de la estabilidad del significado), y del Psicoanálisis, por el otro (especialmente en lo concerniente al concepto de inconsciente y al de transferencia), ha arrojado una nueva luz sobre algunas cuestiones que tradicionalmente han estado en el centro de las preocupaciones abordadas en torno a la traducción. La relación que une/ separa al autor y al traductor, el vínculo entre traducción e interpretación, la oposición (tradicionalmente hablando) entre original y traducción... son los ejes de un nuevo pensamiento sobre el tema que ha obligado a reformular el concepto de originalidad y de autoría y, muy especialmente, a desenmascarar las "intenciones" que nociones tradicionales como la "fidelidad" y la invisibilidad del traductor esconden. Desde el momento que el significado y el conocimiento se contemplan como construcción, o incluso como deseo, hay que repensar necesariamente la transferencia de significado que toda traducción supone.

En la tradición occidental, leer es una actividad que se considera dependiente

\footnotetext{
- Profesora de literatura italiana contemporánea y traducción literaria en la Universidad de Barcelona y coordina el Grupo de Investigación Consolidado CRET sobre Traducción y Multiculturalidad.

Es autora de Studi critici di letteratura italiana contemporanea (2003), Historia de la literatura italiana contemporánea, 2 vols. (2000-2001), La traducción (2001), La recepción literaria (2002), y editora de los volúmenes Ética y política de la traducción en la época contemporánea (2004), Traducción, (sub)versión, transcreación (2005), Traducción y di-ferencia (2006). Editora de la revista electrónica Transfer, dedicada a los estudios de traducción e interculturalidad, que se edita semestralmente en la Universidad de Barcelona.
} 
del significado autoral. Por lo mismo, traducir se ha contemplado como un modo de transferir de manera "protectora" unos significados que se consideran estables, de un texto a otro texto, de una cultura a otra cultura. El pensamiento contemporáneo se opone de manera explícita o implícita a tal planteamiento. Por otro lado, la crítica post-estructuralista insiste en que el sujeto (lector-intérpretetraductor) no puede escapar a sus condicionamientos: su tiempo, su época, su ideología, su formación, su psicología, etc. Por lo que la relación entre el sujeto y el texto siempre se hallará mediada por un proceso de interpretación que, con relación al significado pretendidamente original, tiene más de "creativo" que de "conservador", es más "productor" que "protector". El traductor se perfila como un intermediario que inevitablemente "manipula" el texto, que "negocia" su significado a otra lengua y otra cultura, y a menudo también a otra época y otras circunstancias históricas. Como afirma E. Theodor, el traductor es aquel que hace comprensible lo que antes era ininteligible, y sólo por eso ya debe ser considerado un intérprete por excelencia.

El volumen Traducción y di-ferencia se inscribe en estas coordenadas interpretativas y constituye un punto de partida para la reflexión sobre el fenómeno de la traducción desde un enfoque post-estructuralista como el mencionado. Constituye la tercera entrega de la colección transversal, iniciada en 2004 con la edición de Ética y política de la traducción en la época contemporánea, y continuada, en 2005, con Traducción, (sub)versión, transcreación. Dicha colección está dedicada a la publicación, en formato tradicional y en versión electrónica, de volúmenes conjuntos y/o monografías sobre estudios de traducción centrados en el siglo XX y principios del XXI. Tanto la colección como el presente volumen tienen su origen en la investigación realizada en los proyectos de investigación que lleva a cabo desde hace años el Grupo de investigación de la Universidad de Barcelona "La traducción literaria en la época contemporánea”, y el "CRET-Grupo de Investigación Consolidado sobre Traducción y Multiculturalidad” de la Universidad de Barcelona (España), bajo la coordinación de quien subscribe esta reseña, y en colaboración con otros centros universitarios de ámbito nacional e internacional.

$\mathrm{Al}$ igual que en la entrega anterior, en este volumen han colaborado los miembros del equipo investigador de dicho grupo, así como otros investigadores de otros centros universitarios nacionales e internacionales, vinculados a la investigación mencionada.

Tanto las reflexiones de los traductores sobre su labor como las aportaciones del pensamiento contemporáneo al campo de la traducción a las que hemos hecho referencia constituyen el tema central del presente volumen colectivo.

Los ensayos recogidos en este volumen se inscriben en la reflexión en torno al pensamiento sobre la traducción producido en el siglo XX, ya sea por los traductores o por los críticos, y se aproximan a la traducción desde los parámetros de la crítica post-estructuralista. En general, prevalece la reflexión sobre el significado autoral (Comellas) y el criterio de "fidelidad" o "traición" al texto original, ya sea desde las posiciones de Nietzsche (Bosak), la exposición de la escuela antropofágica del Modernismo brasileño (Lessa), el análisis de la intertextualidad en las prácticas lectoras de la traducción (Godayol), el pensamiento sobre la traducción de F. Fortini (Peña), la reflexión sobre la alteridad en la traducción de la literatura de frontera (Gomes), la traducción cultural y el discurso sobre la traducción en la India (Sales), o la sugerente posición en torno a la traducción presente en la 
obra de Borges (Camps). En el mismo orden de cosas se inscriben algunos ensayos dedicados a analizar el interesante fenómeno de la auto-traducción (Crolla, Zaboklicka y Recio), así como otros que exploran casos concretos de escritores como Tolstói o Yourcenar que dedicaron sus esfuerzos puntuales a la traducción (Gallart, García). La situación de la traducción en Galicia está tratada exhaustivamente en el interesante artículo de Luna. Por su parte, Romano emprende el análisis de las tendencias de traducción vigentes actualmente en Italia. Capítulo a parte lo constituyen los ensayos que abordan la traducción de clásicos en época contemporánea, ya sea en la adaptación de textos medievales (Butinyà) o bien de autores del repertorio clásico francés (Piquer). Un caso concreto de la traducción del francés que analiza la importancia de ésta en la difusión del discurso surrealista se halla muy bien planteado aquí por Mallart. Y, en lo concerniente al ámbito latinoamericano, cabe señalar las interesantes aportaciones de Canós y Serrano, la primera referida al mundo de la cultura chicana, la segunda a la problemática de la traducción al español de México. Por último, mencionar el estudio de las adaptaciones cinematográficas de obras literarias, es decir, el caso de la traducción intersemiótica, abordado por Moya en este volumen.

Desde una pluralidad de puntos de partida, consecuencia de los intereses y especialidades de cada uno de los colaboradores del presente volumen, los ensayos que aquí se recogen reflexionan todos ellos sobre el fenómeno de la traducción como diferencia, en una revisión del papel de la traducción y del traductor que resulta esencial en nuestros días para comprender el verdadero alcance de la mediación cultural que en la traducción, y a través de la traducción, acontece. 